\title{
Disaster management: from a one-sided approach to an inclusive system
}

\author{
Kyoo-Man $\mathrm{Ha}^{1}$ (1)
}

Published online: 3 December 2019

(c) Springer Science+Business Media, LLC, part of Springer Nature 2019

\begin{abstract}
Disaster management principles include incident command system, comprehensive emergency management, integration of operations, and redundancy. The article aims to study how these principles have been used by many nations for the ultimate goal of disaster management. The methodology employed is qualitative content analysis. A one-sided approach to disasters means that application or execution of certain principles is not effectively done, whereas all-inclusive system includes successful application and execution of all principles. The key tenet of the article is that a one-sided approach should be changed into an inclusive paradigm. This means involving all principles and stakeholders and evaluating the factors of risks, politics, resources, and time in disaster management. In this regard, developing nations can learn from their experiences and also from developed nations, and in the process, they can achieve this transformation.
\end{abstract}

Keywords Disaster management principles $\cdot$ Politics $\cdot$ Resources management $\cdot$ The United States · Developing nations

\section{Introduction}

Despite developments in disaster management, its execution has been flawed in a number of occasions. This could also be attributed to the unpredictable nature of disasters. However, with preparation and support from all stakeholders, disasters can be managed with the least adverse impact. We can learn from past disasters such as those listed below:

- Tsunami in Indian Ocean in 2004

- Cyclone Nargis in Myanmar in 2008

- Hurricane Katrina in the US in 2008

- BP oil spill in the US in 2010

- Fukushima earthquake in Japan in 2011

- Typhoon Haiyan in the Philippines in 2013

- Middle East Respiratory Syndrome (MERS) in Korea in 2015

- Seventeen fires in California in 2018

Kyoo-Man Ha

ha1999@hotmail.com

1 Department of Public Policy and Management, Pusan National University, 2, Busandaehak-ro 63beon-gil, Geumjeong-gu, Busan 46241, Korea
From these situations, a number of lapses have been identified. Examples are faulty disaster recognition, foresight failure, groupthink, and limited rationality, among others (Gall et al. 2015; Park 2018; Seppanens and Virrnataus 2015). All these bring us to recognize that changes indeed have to be implemented. The international community is a great resource for data and advanced practices in the field. These should be tapped and maximized to establish effective disaster management (Sword-Daniels et al. 2015).

Disaster management lasts before, during, and after the occurrence of events. Yet, disaster management has been mostly response-centric, though it has had no choice but to include all periods of time in the cases. Disaster management involves interaction among diverse stakeholders; identification of the nature, scale, and place of disaster; and formulation and application of policies, and other actions from relevant disciplines. However, many existing disaster management principles are still limited in terms of inclusive knowledge production or related implementation. Inclusive knowledge is not limited to certain group of people but applies to all people. In particular, many principles were originally from developed nations such as the United States, but not all their experiences, challenges, and actions may be applicable and feasible to the experience and views of other nations on disaster management. With the above in mind, 
it is timely to ask a research question: Are existing disaster management principles applicable to all nations?

The goal of this paper is to investigate how existing disaster management principles have been applied by various nations for the ultimate goal of reducing down human loss, economic damages, and psychological impact. Based on qualitative content analysis as a major methodology, the onesided disaster management principles are rigorously compared to the inclusive disaster management paradigm. The former is to exclude some negative factors (e.g., politicsoriented management, the lack of resources) in the scope of disaster management, whereas the latter is to include all positive (e.g., risk-oriented management, time management) and negative factors into its theoretical application. Therefore, the former here means that either application or execution of some disaster management principles has not been appropriately done. On the other hand, the latter means that both application and execution of all principles are to be fairly done.

To elaborate, both the one-sided principles and the inclusive paradigm are based fundamentally on four existing principles, namely incident command system, comprehensive emergency management, integrated emergency management, and the principle of redundancy. The two different approaches are analyzed by four analytical factors, namely, risk-oriented management, politics, resources management, and time management. As a major finding, this article maintains that a one-sided approach to the field of disaster management has to change. An inclusive paradigm is ideal, and thus it has to be observed in many developing countries.

With the above in mind, the next section examines four disaster management principles and four analytical factors under the subheading of literature review. After elaborating on research design, the paper works on how each of the four disaster management principles has been one-sided in terms of the four analytical factors. Shortly, this article answers what each analytical factor has to do for the four principles in particular to embody the inclusive disaster management paradigm in the future.

\section{Literature review on existing disaster management principles}

A number of articles or books have directly or indirectly touched upon disaster management principles, but did not agree exactly to what they actually are (Boin and Hart 2003; Cuny 2001). Accordingly, some researchers and institutions have attempted to define disaster management principles anew. For example, in 2004, the Australian governments stated that the basic principles of disaster management should include the comprehensive aspect and integrated feature of disaster management, when reflecting that disaster management is about dealing with a wide scale and variety of hazards (EMA 2004).

In 2007, Wayne Blanchard, with the support of the U.S. Emergency Management Institute (EMI), chose eight characteristics of emergency management, specifically comprehensive, progressive, risk-driven, integrated, collaborative, coordinated, flexible, and professional aspects (IAEM 2007). These characteristics or principles have been endorsed by US institutions, including the Emergency Management Accreditation Program and the National Emergency Management Association. Also, they have been endorsed by international institutions, including the international association of emergency managers (IAEM) and the Singapore Civil Defence Force.

Among a number of disaster management principles, four principles have been supported in general, based on literature review. In particular, these four principles have been directly or indirectly identified via the application materials of certified emergency manager (CEM). The authorities of IAEM have prepared the CEM materials with the financial support of the US Federal Emergency Management Agency (FEMA). More than 5,000 professionals in the international community, to include many from the United States, have contributed to the development of these four principles (IAEM 2019).

\subsection{Incident command system}

A series of wildfires occurred in California in the early 1970s. Although all participating agencies did their best to extinguish rapidly moving wildfires, they came to face many critical problems regarding communication or coordination. After the wildfires were put out, the Firefighting Resources Organized for Potential Emergencies established an incident command system resulting from lessons learned from this disaster.

As a standardized approach in the United States, an incident command system encourages all emergency responders to use an integrated institutional structure, which may reflect the demands and complexities of various incidents. An incident command system includes fundamental subprinciples, including having common terminology, span of control, incident action plan, comprehensive resources management, integrated communication, and multi-agency coordination (OSHA 2015).

However, in some Asian countries such as Taiwan, incident command system has not been rigorously practiced, due to different concepts, organization levels, and cultures (Lam et al. 2010). In particular, local residents in Taiwan have developed own viewpoints on the mode of disaster response, depending on their socioeconomic culture. As a result, those residents have not succeeded in promoting ICS in the region. 


\subsection{Comprehensive emergency management}

In the United States, multiple organizations work for disaster management at the federal level. Thus, many governors worry about the lack of disaster management coordination at the state level as well as at the federal level. During the Carter administration in 1979, the FEMA was newly set up as a single federal agency. The National Governors' Association suggested the principle of comprehensive emergency management as a guideline for the FEMA.

Comprehensive emergency management takes into account four phases of emergency management lifetime: emergency prevention/mitigation, preparedness, response, and recovery. All professionals or stakeholders are to participate in disaster management while they fight against all kinds of hazards. Furthermore, the field of disaster management systematically deals with all impacts of disasters to include not only their physical impact but also their social impact (National Governors' Association 1979).

However, comprehensive emergency management has not been well executed in Korea, due to a different environment. Regarding the participation of all professionals in disaster management, mainly two professionals have been allowed to work for the Korean field such as firefighters and civil engineers (NFA 2019). Despite the recognition of comprehensive emergency management, those two professionals have tried to dominate the field with the cooperation of elected politicians.

\subsection{Integration of operations or integrated emergency management}

In the beginning of the 1980 s, the United States tried to create a new culture in the field of disaster management, which was far beyond a method of disaster management. The nation began to treat the field of disaster management as a "joint enterprise" (Bobrowsky 2013). Not only during the occurrence of a disaster but also during normal times, the field wants to address unity among governments, private partners, voluntary organizations, the military, mass media, and other local communities altogether. In another aspect, the field wants to address various partnerships between/ among local, state, and federal levels. In doing so, various networks or related networking (not a central body or organization) among stakeholders are being supported like a joint corporation. This shows that an integrated emergency management emphasizes the unity of disaster management efforts more than any other specific function.

As actual experiences on new culture of joint enterprise, researchers in the field have made efforts to work for multidisciplinary researches by connecting ecology, geography, engineering, psychology, law, liberal arts, and other disciplines, as well as public administration and business management. Also, many local communities have come to work on mutual aid agreements (MAA) to facilitate rapid emergency supports. In terms of international cooperation, the EMI began to allow foreigners to access its Independent Study Program in 2010s. As a result, many foreigners have accessed to advanced knowledge and information for their countries. Besides, the high extent of international cooperation such as international aids, the participation of international non-governmental organizations (NGOs), emergency information delivery, and others has been substantially addressed in many regional disaster cases.

Notwithstanding, the principle of integrated emergency management has not been successfully applied to other nations. As such, Indonesia has not successfully implemented the issue of communication among stakeholders, while dealing with a series of natural disaster (Wikoff 2014). As an evidence, it has not been easy for quite a few Indonesian stakeholders to find out appropriate phone numbers during or after emergency and, thus, failed to integrate them.

\subsection{Redundancy}

The principle of redundancy was positively applied in the field of technology. However, a majority of management theories tried to reduce the extent of unnecessary redundancy in their application. Notwithstanding, the field of disaster management began to consider redundancy to be an excess capacity, which may supply the field with alternatives to safeguard against its component failure. As such, in the event a component of disaster management fails, the whole field does not fail completely, thanks to redundancy.

Similarly, having redundancies in place for equipment and people resources are important in critical times during a disaster. For example, with excess capacity, the likelihood of extending and speeding up rescue operations is higher. Redundancy has been reflected in emergency warning and evacuation. Both emergency warning and immediate evacuation interact with multiple technical systems and complicated social processes. The effectiveness of warning and evacuation depends on reliable individual subparts in the field. Therefore, planned redundancy, including emergency warning and evacuation, should be incorporated into emergency operation plans. Otherwise, human loss would not be reduced (Streeter 1991).

Despite the above fact, the principle of redundancy has not been well executed in many developing nations in Asia, South America, and Africa. Primarily because those nations have not possessed robust economy, they have not prepared for redundant resources against disaster (Nowell 2017). Haiti has continued to suffer from earthquakes, due to the lack of redundancy (ex., the application of anti-seismic technology) in its national disaster management. 
Note that these illustrations did not come from developing nations, but from developed ones, particularly from the United States. The United States assessed its failures and successes in this field over the past century and worked toward an overall improvement of its disaster management. Certainly, other nations can learn from the US experience inasmuch as the United States can also learn from other nations' experiences and developments in the field. Universal application may not be feasible so country-specific experiences need to be considered. Strengths and weaknesses and positive and negative points of existing systems in other individual nations need to be evaluated.

Despite the characteristics of existing disaster management principles, it is also equitable to investigate whether those principles have negative aspects or not. Many individuals have assumed that such principles may be universally applied to anybody, anywhere, or anytime because those are called as principles in terms of disaster management. Principles are basic truths that explain the relationship between cause and effect in the field.

Nevertheless, some researchers have tried to improve those principles via their own criteria or perspectives. However, they have not directly addressed the negative aspects of those principles. Rather, they have indirectly hinted on the aspect of negative principles (FEMA 2013; Prieur 2012). To this point, this paper is a pioneer study on the real value of existing disaster management principles in the international community, including not only the positive points but also the negative points so that they are not applied in disaster management in the future.

While considering the four principles above, this paper has chosen eight disaster cases to study. Included are the Indian Ocean tsunami, cyclone Nargis in Myanmar, hurricane Katrina in Louisiana, BP oil spill in the Gulf of Mexico, Fukushima earthquake, typhoon Haiyan in the Philippines, MERS in Korea, and the recent 17 fires in California. Each case has been classified as a catastrophe in the region, when thinking related human loss, economic damages, and other impacts (Mirzaee 2019).

These eight cases have been satisfactory enough in terms of the intention of selection, the justification of preference, and the relevance to the main theme. As such, it is necessary to study not only natural disaster but also man-made emergency for the goal of effectively studying the whole scope of disaster management. Also, this paper wanted to study the issue of disaster management in both developed nations (in particular the United States) and developing nations in the viewpoint of geography. Furthermore, each disaster case should have appropriate contexts regarding the above-mentioned four principles (or following four analytical factors to include risk-oriented management, politics, resources management, and time management).

\section{Research design}

Disaster management, including its existing principles, has been interpreted in many ways in the field. Depending on individual perspectives, those guiding principles have been differently or appropriately interpreted to each case. In other words, those principles are context-dependent, which is open to interpretation (Aitken and FitzGerald 2017; MacAskill and Guthrie 2014). Therefore, the methodology of this paper has to address all possible interpretations during analysis.

For diverse interpretation, this paper has not used many quantitative data but significant qualitative data. Hence, the major methodology used is qualitative content analysis. In fact, qualitative content analysis is to search for, identify, interpret, and re-write appropriate qualitative texts and contexts into the right places. Therefore, the process of qualitative content analysis includes three steps such as preparing, organizing, and reporting (Elo and Kyngas 2008; Mayring 2000).

To ensure that any important interpretation is not missed regarding disaster management principles, this paper has tried to include many significant contextual knowledge, data, or interpretation on disaster management using Internet search engines. In doing so, this article used keywords such as 'emergency management principles,' 'fundamentals of disaster management,' or specific disaster management principles. Hence, this paper has utilized 49 sample publications, including 33 articles, 6 books, and 10 online documents. Also, the period of those publications was between 1979 and 2019.

In Fig. 1, the paper compares two distinctive approaches: the one-sided disaster management where some factors are excluded thereby causing an imbalance and the inclusive disaster management where there is balance in all the important factors considered. In other words, the one-sided approach is a failure in terms of applying or executing certain disaster management principle, whereas the inclusive paradigm is a success in application and execution of all disaster management principles. The article maintains that one-sided principles need to be changed to the inclusive paradigm.

To elaborate, there is imbalance when not all the four factors are addressed or included. If one or two, in this case politics and resources, are outside the sphere of disaster management, then the respective stakeholders will be neither completely informed nor involved. In an inclusive approach, all factors are considered by all concerned stakeholders. The system works because there is action and interaction between and among stakeholders observing the principles of disaster management. 


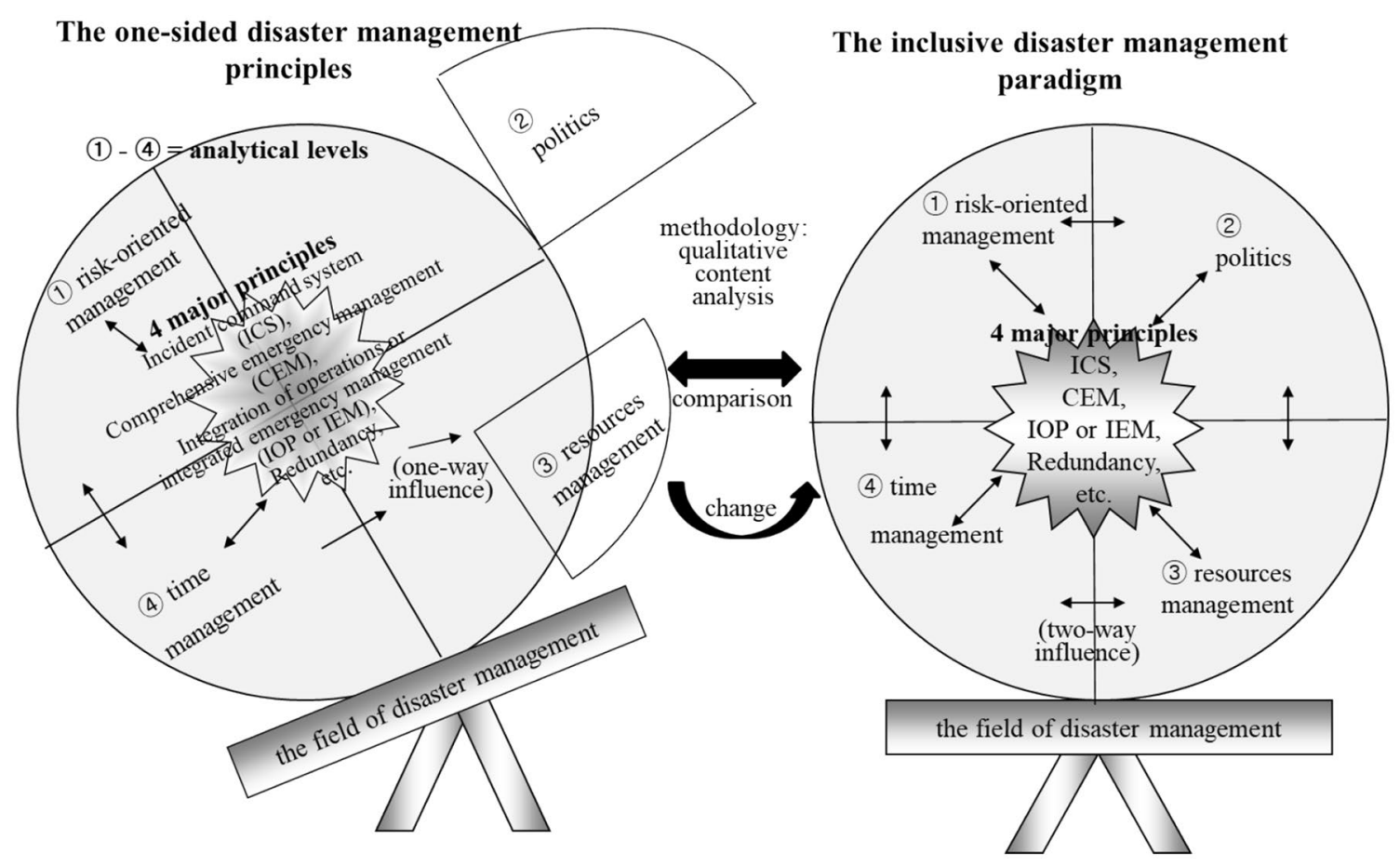

Fig. 1 Analytical framework

\section{One-sided disaster management principles}

\subsection{Risk-oriented management}

All four existing disaster management principles have strongly advocated for risk-oriented management for the goal of disaster management (Rivera et al. 2015). Similarly, the case of BP oil spill in the US has effectively shown the issue of risk-oriented management (e.g., the complicated process of gathering information on how to stop the oil spill under the sea during the limited time, etc.). Elaborating on the point, incident command system has shown the importance of risk-oriented management by providing a standardized institutional structure for the phase of disaster response. Comprehensive emergency management has addressed this by evaluating all risks identified in various types of disasters.

In a similar token, while emphasizing unity among diverse stakeholders, integration of operations or maintaining networks among stakeholders is useful in providing support to risk-oriented management. Without relying on riskoriented management, integrated emergency management could not set up appropriate networks among all stakeholders (Sheffi 2001). Further, the implementation or practice of redundancy, while preparing for various alternatives, has indirectly recognized the significance of risk-oriented management.

\subsection{Politics}

Although all four principles have addressed risk-oriented management, they have not equally touched upon the entity of politics in their theoretical process (Prater and Lindell 2000). Some practitioners have come to complain against the substantial dominance of politics in managing hurricane Katrina (e.g., unequal treatment for minority, etc.) and Fukushima nuclear leakage (e.g., Japanese government's failure in information sharing with residents or outsiders). For example, incident command system has disregarded the negative aspect (e.g., political corruption) of politics-oriented management while providing positive (e.g., productive disaster management) sub-principles. Comprehensive emergency management has not clearly pointed out the entity of politics, which is opposite to all-risk management.

Similarly, although dirty politics has frequently existed during the disaster management networking process, integrated emergency management has not clearly specified its existence at all. The principle of redundancy has focused on arranging excessive resources to deal with disasters, but the influence of politics on the concept of redundancy or its evolution has not been discussed (Pidgeon and O'Leary 2000).

\subsection{Resources management}

Whereas both comprehensive emergency management and integration of operations have not mentioned much about 
resources management, they have been directly included in theories of incident command system and the principle of redundancy. Paradoxically, the experience of typhoon Haiyan in the Philippines (as a developing nation) has come to show the case of resources management (e.g., the lack of emergency stockpiles). To elaborate, comprehensive emergency management and integration of operations have maintained their focus on disaster management such as the comprehensive aspect of disaster management and networking among stakeholders, particularly without the basis of resources management (Ferbar 2016).

On the contrary, incident command system and the principle of redundancy have indicated that resources are abundant in the field of US disaster management, but their distribution is unequal (Kanji and Patel 2015). Under this assumption, these two principles have provided their own themes. Incident command system has emphasized the management of diverse resources to include individuals, teams, supplies, equipment, and facility. The principle of redundancy has also supported the use of memorandum of understanding to reduce the extent of unequal resource distribution among different areas.

\subsection{Time management}

All four principles have not directly specified time management during their application processes, literally speaking. Rather, those principles have just indirectly accounted for time. Of course, it is true that the case of standard operating procedure of line department like fire services has directly specified time management. With all in mind, time, especially in relation to quick decisive action, is always paramount in disaster management. Any delay and indecisive action can have a further adverse effect on a disastrous situation (Arain 2015; Lovreglio et al. 2015; Waring 2015). The matter of time has been seriously emphasized in managing the outbreak of pandemic MERS in Korea and the 17 fires in the state of California due to drought and winds. Therefore, the principles of disaster management have to always consider the element of time. Time management has indirectly affected each, to say the least.

\section{Inclusive disaster management paradigm}

\subsection{Risk-oriented management}

There are three kinds of risk in the field of disaster management: human loss, economic damages, and psychological impact. In general, the field has not succeeded in equally addressing all the three risks. The physical impact, such as human loss and economic damages, in many occasions, has been managed more heavily than social impact such as psychological impact. The four existing principles have attempted to include all risks in their theoretical applications.

The issue of risk data availability and accuracy has been much discussed and supported in the field. While risk data availability is to define, gather, and process various risk data according to related requirements, risk data accuracy is a factor of data quality (Basel Committee on Banking Supervision 2013). Without data availability and accuracy, it would be hardly possible for the field to make effective decisions. On the way to the inclusive paradigm, all four principles need to be keenly aware of risk data availability and accuracy to make risk-informed decisions.

\subsection{Politics}

Many stakeholders have done their best to deal with disaster using advanced technology, but at times, they have failed due to politics. Political cover-up and infighting by some sectors' interests have affected disaster management. In the inclusive paradigm, all four principles should have touched upon the influence of politics over disaster management.

In terms of governance, the field of disaster management is decentralizing its decision-making mechanisms toward democracy, although the process is taking time. Under lessdemocratic systems, the field of disaster management has been dominated by the centralized decision-making mechanisms. Even though local governments are the first line of disaster defense, the central government has played a key role in managing disasters in less-democratic systems. Some gaps among disaster management decentralization, policies, and other practices also continue mainly because politics plays a role in distorting decentralized decision-making mechanisms (Blackburn 2014).

\subsection{Resources management}

Toward the inclusive paradigm, both comprehensive emergency management and integrated emergency management must initiate including more aspects on resources management in their application. In addition, although incident command system and the principle of redundancy have clearly mentioned related resources management, they have to improve on their theories, particularly when applying their discourses for other regions in the international community.

To elaborate, it is inevitable for all four principles to specify the lack of resources in the poor regions as well as how to overcome the unequal distribution of resources among stakeholders. As such, although voluntary organizations in the United States have preferred cash donations, those in the poor regions are willing to receive any kind of donation. Thus, all four principles have to add how to manage the 
lack of disaster management resources regardless of national boundary (Hamdan 2015).

\subsection{Time management}

Due to time management, it has been widely acknowledged that the field of disaster management has to work on its alternatives within a short period of time. In particular, the speed of disaster response or that of disaster recovery has been considered a key factor for the success of disaster management. A major success indicator is how a quick and decisive action is able to mitigate and reduce impacts of a disaster. On the other hand, failure can be measured from the magnitude of serious adverse impacts resulting from inaction or inadequate action.

For the inclusive paradigm, it is essential for the field of disaster management to create a schedule on disaster management (Norling 2013). When reflecting that a schedule plays a role in forming time components, a comprehensive schedule may be used as a baseline for disaster management. By breaking down the work structure into relevant parts, the schedule will reflect not only a realistic timeframe but also the sequence of disaster management.

\section{Discussion}

Based on the above comparison, one-sided principles also explain many aspects of disaster management, but they are neither perfect nor balanced. They have unexpected aspects or incomplete application under a different environment. With all these in mind, if one-sided principles are not replaced, at the very least, they need to be systematically supplemented with inclusive approaches. In the end and by itself, the paradigm will actually shift into an all-inclusive disaster management.

The inclusive disaster management paradigm is a strategic framework; it covers all elements and corners of disaster management. With all elements working together against diverse hazards, better strategies on how to fight against disasters can emerge (Queensland Government 2010). Hence, application and execution of all disaster management principles will be successfully done.
Eight disaster cases, which have just been analyzed, include not only natural disaster but also man-made emergency. The response mechanism between them has been very similar, but the risk factors have been very different. Some events have been natural disasters such as Indian Ocean tsunami and cyclone Nargis, but they have continued to cause man-made emergencies such as the outbreak of measles, malaria, cholera, or other waterborne illnesses. Of course, it has been much harder for the field to deal with this kind of disaster than pure natural disaster or pure man-made emergency.

To deal with the outbreak of pandemic diseases following a natural disaster, the inclusive disaster management paradigm must be effectively addressed (Myint et al. 2011). In other words, the inclusive paradigm may address the complicated aspects of disaster better than the one-sided approach in particular by fully utilizing all means possible to include information communication, monitoring, surveillance, risk assessment and interventions, resource allocation, strategies, etc.

In terms of interaction or influence, the one-sided disaster management principles and the inclusive disaster management paradigm have taken different directions. The former is incomplete and has not found its way around politics. A oneway influence has been applied also around resources management. Under the inclusive paradigm, a two-way influence is practiced around all the four principles with reference to all four analytical factors.

Similarly, two approaches have shown different applicability between developed nations and developing nations. In Table 1, the one-sided disaster management principles have not been able to explain all four analytical factors in many nations. On the contrary, the inclusive disaster management paradigm may well address them regardless of national boundary. Thus, the international field of disaster management may use the inclusive paradigm as the appropriate model.

Regarding the dynamics of many developing nations, they have been faced with political conflicts, poor performance of regional authorities, socioeconomic turmoil, the inefficiency of financial system, resource constraints, and other environmental challenges more seriously than developed nations (Al-Nammari and Alzaghal 2015; Hochrainer-Stigler et al.

Table 1 Comparison between the applicability of one-sided principles and the applicability of the inclusive paradigm

\begin{tabular}{lll}
\hline Four analytical factors & Two approaches & \\
\cline { 2 - 3 } & One-sided disaster management principles & Inclusive disaster management paradigm \\
\hline Risk-oriented management & Developed nations and developing nations & Developed nations and developing nations \\
Politics & - & Developed nations and developing nations \\
Resources management & Developed nations & Developed nations and developing nations \\
Time management & Developed nations and developing nations & Developed nations and developing nations \\
\hline
\end{tabular}


2015). To this point, developing nations have to incorporate all components into their disaster management framework following examples from many developed nations.

While decreasing the differences between the theory of inclusive disaster management paradigm and the actual conditions in developing countries or even in some developed nations, the field of disaster management may better address the dynamics of disaster management. For example, the field can facilitate the process of emergency operation plans in developing nations or in some developed countries, particularly by grasping or including all analytical factors into their management (Asghar et al. 2006).

The one-sided disaster management principles have seriously developed their own rhetoric. However, they have disregarded the importance of disaster management reality, such as politics-oriented management, the lack of disaster management resources, and others. Although the one-sided principles claim the reflection of harsh realities, not all stakeholders have fully acknowledged the related contexts. Therefore, the one-sided principles must balance their existing rhetoric with reality more systematically than what is being done at present (Scolobig et al. 2015).

Moreover, the inclusive disaster management paradigm may be used as a real-world application, as it includes various real-world factors into the field of disaster management. Furthermore, when reflecting on the fact that the inclusive paradigm interacts with all real-world factors, it may be applicable to real situations, particularly by including realistic constraints and variables (Jabbarzadeh et al. 2014).

When analyzing that the inclusive disaster management paradigm includes not only the analyzes of positive aspects but also of negative aspects on disaster management, the field of disaster management may identify the whole area of disaster or disaster management in real time. With functions of software applications or a satellite image, the inclusive paradigm may provide the holistic viewpoint of hazards, emergency, disaster, and risks for all stakeholders at near real time (Balkaya et al. 2015). Further, given that the inclusive paradigm covers many aspects of constraints on disaster management, it leads to being a heterogeneous paradigm as well (Noran 2014; Su et al. 2015).

To spread the case of inclusive disaster management paradigm, the educators in the field of disaster management may include it into their curricula. While pointing out the difficulties of disaster management, educators can elaborate on the negative aspects of the one-sided principles via their educational materials. These combined curricula may provide the overview of disaster management more clearly than the previous or existing curricula.

Similarly, educators may collaborate with governments, industries, NGOs, military, mass media, and other communities when necessary. Based on collaboration among those stakeholders, educators may spread the necessity or the potential benefits of applying the new paradigm (Thayaparan et al. 2014). In doing so, the inclusive paradigm will seep into the corner of disaster management field.

At the same time, various disaster management practitioners may use the inclusive paradigm as part of their management tools or training materials. In other words, when thinking that many practitioners always need their theoretical background or criteria before, during, and after a disaster, they may pick up the inclusive paradigm and then apply it to their management process or to exercise and training courses (Alfred et al. 2015).

\section{Conclusion}

The paper has made all efforts to examine how several disaster management principles have been applied by various nations to include developed nations and developing nations. When thinking that both one-sided disaster management principles and the inclusive disaster management paradigm have been clearly identified and then systematically compared, the goal of this paper has been satisfactorily achieved.

A key conclusion is that for overall improvement of disaster management, all the principles have to be considered, and all stakeholders should work together during implementation. Certain elements may not work for developing nations, but on the whole, both developed and developing nations need to address the risks, politics, resources, and time concerns that come with managing disasters.

The United States is a rich source of both failures and successes in this field. Therefore, many useful insights can be gained from their experience, especially as other nations shift to their own all-inclusive disaster management paradigm.

To substantially expand the use of inclusive disaster management paradigm in the international community, each stakeholder has to seek own assignment. In particular, it is necessary for educators or trainers to start including the inclusive paradigm into their disaster management curricula or exercise and training courses. Also, various disaster management practitioners may use it as their theoretical criteria when dealing with terrible disasters in the community.

The inclusive disaster management paradigm is still a sort of new or improved model on disaster management. Thus, multiple researchers may consider the inclusive paradigm to be a new research agenda. They may further investigate the legitimacy of the inclusive paradigm for their own disaster management. Alternatively, they may depend on the inclusive paradigm while studying their own subjects. In so doing, such researchers will contribute to mitigating human loss, economic damages, and psychological impact wherever they stay. 


\section{Compliance with ethical standards}

Conflict of interest The author declares that he has no conflict of interest.

\section{References}

Aitken P, FitzGerald G (2017) Principles of disaster management. Academia. https://nursing.flinders.edu.au/documents/File/Peter \%20Aitken,\%20Gerry\%20Fitzgerald.pdf. Accessed 3 May 2019

Alfred D, Chilton J, Connor D, Deal B, Fountain R, Hensarling J, Klotz L (2015) Preparing for disasters: education and management strategies explored. Nurse Educ Pract 15(1):82-89. https:// doi.org/10.1016/j.nepr.2014.08.001

Al-Nammari F, Alzaghal M (2015) Towards local disaster risk reduction in developing countries: challenges from Jordan. Int J Disaster Risk Reduct 12:34-41. https://doi.org/10.1016/j.ijdrr.2014.11.005

Arain F (2015) Knowledge-based approach for sustainable disaster management: empowering emergency response management team. Proc Eng 118:232-239. https://doi.org/10.1016/j.proen g.2015.08.422

Asghar S, Alahakoon D, Churilov L (2006) A comprehensive conceptual model for disaster management. J Hum Assist 1360(0222):1-15

Balkaya C, Casciati F, Casciati S, Faravelli L, Vece M (2015) Real-time identification of disaster areas by an open-access vision-based tool. Adv Eng Softw 88:83-90. https://doi.org/10.1016/j.adven gsoft.2015.06.002

Basel Committee on Banking Supervision (2013) Principles for effective risk data aggregation and risk reporting. Bank for International Settlements, Hong Kong

Blackburn S (2014) The politics of scale and disaster risk governance: barriers to decentralisation in Portland, Jamaica. Geoforum 52:101-112. https://doi.org/10.1016/j.geoforum.2013.12.013

Bobrowsky PT (2013) Encyclopedia of natural hazards. Springer, Netherlands

Boin A, Hart P (2003) Public leadership in times of crisis: mission impossible? Public Adm Rev 63(5):544-553. https://doi. org/10.1111/1540-6210.00318

Cuny FC (2001) Principles of disaster management lesson 14: Criteria for assessing a program. Prehosp Disaster Med 16(4):303-306. https://doi.org/10.1017/S1049023X00043466

Elo S, Kyngas H (2008) The qualitative content analysis process. J Adv Nurs 62(1):107-111. https://doi.org/10.111 1/j.1365-2648.2007.04569.x

Emergency Management Australia (EMA) (2004) Emergency management in Australia: concepts and principles. EMA, Commonwealth of Australia

Federal Emergency Management Agency (FEMA) (2013) Fundamentals of emergency management. Emergency Management Institute, Emmitsburg, MD

Ferbar TL (2016) Comprehensive energy resource management for essential reduction of the total cost. J Mech Eng 62(11):685-694. https://doi.org/10.5545/sv-jme.2016.3994

Gall M, Nguyen KH, Cutter Susan L (2015) Integrated research on disaster risk: is it really integrated? Int J Disaster Risk Reduct 12:255-267. https://doi.org/10.1016/j.ijdrr.2015.01.010

Hamdan F (2015) Intensive and extensive disaster risk drivers and interactions with recent trends in global political economy, with special emphasis on rentier states. Int J Disaster Risk Reduct 14(3):273-289. https://doi.org/10.1016/j.ijdrr.2014.09.004

Hochrainer-Stigler S, Mechler R, Mochizuki J (2015) A risk management tool for tackling country-wide contingent disasters: a case study on Madagascar. Environ Model Softw 72:44-55. https://doi. org/10.1016/j.envsoft.2015.06.004

IAEM (2019) Official website of IAEM. https://www.iaem.com/. Accessed 6 Aug 2019

International Association of Emergency Managers (IAEM) (2007) Principles of emergency management. https://www.iaem.com/ documents/EMPrinciples091107.pdf. Accessed 30 May 2019

Jabbarzadeh A, Fahimnia B, Seuring S (2014) Dynamic supply chain network design for the supply of blood in disasters: a robust model with real world application. Transp Res E 70:225-244. https://doi. org/10.1016/j.tre.2014.06.003

Kanji R, Patel P (2015) Technology in times of disaster: an Indian step towards resource management. Proc Eng 107:73-80. https://doi. org/10.1016/j.proeng.2015.06.060

Lam C, Lin MR, Tsai SH, Chiu WT (2010) A pilot study of citizens' opinions on the Incident Command System in Taiwan. Disasters 34(2):447-469. https://doi.org/10.1111/j.1467-7717.2009.01137.x

Lovreglio R, Ronchi E, Nilsson D (2015) A model of decision-making process during pre-evacuation. Fire Saf J 78:168-179. https://doi. org/10.1016/j.firesaf.2015.07.001

MacAskill K, Guthrie P (2014) Multiple interpretations of resilience in disaster risk management. Procedia Econ Finance 18:667-674. https://doi.org/10.1016/S2212-5671(14)00989-7

Mayring P (2000) Qualitative content analysis. Forum Qual Sozialforschung / Forum: Qual Social Res 1(2):Art. 20. https://nbn-resol ving.de/urn:nbn:de:0114-fqs0002204. Accessed 22 August, 2019

Mirzaee S, Fannon D, Ruth M (2019) A comparison of preference elicitation methods for multi-criteria design decisions about resilient and sustainable buildings. Environ Syst Decis. https://doi. org/10.1007/s10669-019-09726-2

Myint, NW, Kaewkungwal, J, Singhasivanon, P, Chaisiri, K, Panjapiyakul, P, Siriwan, P, Mallik, AK, Nyein, SL, Mu, TT (2011) Are there any changes in burden and management of communicable diseases in areas affected by Cyclone Nargis? Conflict Health 5:Article no. 9. https://doi.org/10.1186/1752-1505-5-9

National Fire Agency (NFA) (2019) Official website of NFA (in Korean). https://www.nfa.go.kr/nfa/. Accessed 1 September, 2019

National Governors' Association (1979) Comprehensive emergency management: a governor's guide. National Governors' Association, Washington, D.C.

Noran O (2014) Collaborative disaster management: an interdisciplinary approach. Comput Ind 65(6):1032-1040. https://doi. org/10.1016/j.compind.2014.04.003

Norling B (2013) Effective time management in post-disaster reconstruction. 2013 QLD Central Regional Conference, Bundaberg Australia, October 13. https://theyellowcompany.com.au/wp-conte nt/uploads/2013/10/Effective-Time-Management-in-Post-Disas ter-Reconstruction1.pdf. Accessed 9 September, 2019

Nowell B (2017) Redundancy as a strategy in disaster response systems: a pathway to resilience or a recipe for disaster? Contingencies Crisis Manage 25(3):123-135. https://doi. org/10.1111/1468-5973.12178

Occupational Safety \& Health Administration (OSHA) (2015) What is an incident command system? https://www.osha.gov/SLTC/etool s/ics/what_is_ics.html. Accessed 12 March, 2019

Park M (2018) California fire explodes in size, is now largest in state history. https://edition.cnn.com/2018/08/06/us/california-fires/ index.html. Accessed 22 May, 2019

Pidgeon N, O’Leary M (2000) Man-made disasters: why technology and organizations (sometimes) fail. Saf Sci 34(1/3):15-30. https ://doi.org/10.1016/S0925-7535(00)00004-7

Prater C, Lindell M (2000) Politics of hazard mitigation. Nat Hazards Rev 1(2):73-82. https://doi.org/10.1061/ (ASCE) 1527-6988(2000)1:2(73)

Prieur M (2012) Ethical principles on disaster risk reduction and people's resilience. Council of Europe, Strasbourg 
Queensland Government (2010) Disaster management strategic policy framework. Queensland Government, the State of Queensland.

Rivera C, Tehler H, Wamsler C (2015) Fragmentation in disaster risk management systems: a barrier for integrated planning. Int J Disaster Risk Reduct 14(4):445-456. https://doi.org/10.1016/j.ijdrr .2015.09.009

Scolobig A, Prior T, Schroter D, Jorin J, Patt A (2015) Towards people-centered approaches for effective disaster risk management: balancing rhetoric with reality. Int J Disaster Risk Reduct 12:202212. https://doi.org/10.1016/j.ijdrr.2015.01.006

Seppanen H, Virrnataus K (2015) Shared situational awareness and information quality in disaster management. Saf Sci 77:112-122. https://doi.org/10.1016/j.ssci.2015.03.018

Sheffi Y (2001) Supply chain management under the threat of international terrorism. Int J Logistics Manag 12(2):1-11. https://doi. org/10.1108/09574090110806262

Streeter CL (1991) Redundancy in social systems: implications for warning and evacuation planning. Int J Mass Emerg Disasters 9(2):167-182

Su X, Zhang M, Bai Q (2015) Dynamic task allocation for heterogeneous agents in disaster environments under time, space, and communication constraints. Comput J 58(8):1776-1791. https:// doi.org/10.1093/comjnl/bxu157

Sword-Daniels VL, Twigg L, Loughlin SC (2015) Time for change? Applying an inductive timeline tool for a retrospective study of disaster recovery in Montserrat, West Indies. Int J Disaster Risk Reduct 12:125-133. https://doi.org/10.1016/j.ijdrr.2014.12.006

Thayaparan M, Malalgoda C, Keraminiyage K, Amaratunga D (2014) Disaster management education through higher education-industry collaboration in the built environment. Proc Econ Finance 18:651-658. https://doi.org/10.1016/S2212-5671(14)00987-3

Waring A (2015) Managerial and non-technical factors in the development of human-created disasters: a review and research agenda. Saf Sci 79:254-267. https://doi.org/10.1016/j.ssci.2015.06.015

Wikoff K (2014) Communication lessons learned from the Indian Ocean tsunami and other natural disasters. Blog at WordPress. com. https://katherinewikoff.com/2014/12/26/communicationlessons-learned-from-the-indian-ocean-tsunami-and-other-natur al-disasters/. Accessed 3 Sept 2019 